\title{
Cinemas de rua ao longo do Vale do Rio Tijucas (SC): expressões da cultura e marcadores do desenvolvimento regional
}

\author{
Renata Rogowski Pozzo \\ Universidade do Estado de Santa Catarina - Laguna - SC -Brasil \\ ORCID: https://orcid.org/0000-0003-3965-4813 \\ Luís Eduardo Candeia \\ Universidade do Estado de Santa Catarina - Laguna - SC -Brasil \\ ORCID: https://orcid.org/0000-0002-8073-5001
}

\section{Resumo}

O presente artigo parte de uma investigação sobre o circuito exibidor de cinemas de rua do Vale do Rio Tijucas (SC), localizado no litoral centro-norte catarinense, questionando como aspectos relativos à abertura, ao funcionamento e ao fechamento dessas salas conectam-se com o processo de desenvolvimento regional deste território entre as décadas de 1920 e 1970. Ao longo do Vale do Rio Tijucas, estiveram em funcionamento durante o século XX seis salas de cinema de rua: os Cines Manoel Cruz (1926/193-) e Lohse (195-/19--) em Tijucas; os Cines Canelinha (1956/19--) e Astória (1953/19--), em Canelinha; o Cine São João (1961979) em São João Batista e; o Cine Lindoia (1954/19--), em Nova Trento. A hipótese é que a implantação deste circuito é manifestação cultural da sociedade e as salas podem ser abordadas como importantes marcadores do desenvolvimento regional. A análise da formação desse circuito exibidor revela um processo de desenvolvimento regional complexo, com continuidades e descontinuidades históricas, resultado de múltiplas determinações concernentes à configuração regional. Metodologicamente, a pesquisa partiu da ordem próxima, as salas de cinema tomadas em sua particularidade e, a partir de uma análise histórica sobre cada uma delas, chegou-se às questões de ordem mais ampla, ou seja, as questões de desenvolvimento regional. Os levantamentos empíricos foram analisados à luz de pesquisas históricas e teóricas acerca de três campos: o desenvolvimento regional catarinense, a geografia do cinema e o debate acerca da relação entre cinema, cultura e desenvolvimento.

Palavras-chave: Desenvolvimento regional. Sala de cinema de rua. Vale do Rio Tijucas (SC).

Street movie theaters along the Tijucas River Valley (Santa Catarina, Brazil): expressions of culture and markers of regional development

\section{Abstract}

This article is based in an investigation about the exhibition circuit of street movie theaters along the Tijucas River's valley, in Santa Catarina's state, located in the northern center portion of the coast, questioning about how opening, operational and closing aspects of this spaces connects with the regional development process in this territory in between 
1920's and 1970's. Six street movie theaters have worked beside the Tijucas River's Valley during the $20^{\text {th }}$ century, being the Cine Manoel Cruz (1926/193-) and Cine Lohse (195-/19--), in Tijucas; the Cine Canelinha (1956/19--) and Cine Astória (1953/19--), in Canelinha; the Cine São João (196-/1979) in São João Batista; and the Cine Lindoia (1954-19--), in Nova Trento. The hypothesis exposed here is that the implantation of this movie theater's circuit becomes society's cultural manifestations, and these spaces can be used to mark different stages in the development of the region. The growth analysis of this exhibition's circuit reveals a complex deployment of the regional development, with continuities and breaks throughout history, resulting in multiple statements about regional conformation. Methodologically, this research has started by the historical analysis of the singularities shown by each one of the street movie theaters, then, these results have drowned up a higher question: the development and growth of the territory. These initial conclusions were improved with the help of historical and theorical research, based in three different areas: the Santa Catarina's regional development, the cinema's geography, and the discussion about the relation between cinema, culture, and development.

Keywords: Regional development. Street movie theaters. Tijucas River Valley (Santa Catarina, Brazil).

\section{Viejos cines callejeros a lo largo del Valle del Río Tijucas (Santa Catarina, Brasil): expresiones de cultura y marcadores de desarrollo regional}

\section{Resumen}

Este artículo es parte de una investigación sobre el circuito de viejos cines callejeros en el Vale do Rio Tijucas (SC), ubicado en la costa centro-norte de Santa Catarina, cuestionando cómo se relacionan aspectos de la apertura, funcionamiento y cierre de estas salas con el proceso de desarrollo regional de este territorio entre las décadas de 1920 y 1970. A lo largo del Valle del río Tijucas, seis cines estuvieron en funcionamiento durante el siglo XX: los Cines Manoel Cruz (1926 / 193-) y Lohse ( 195- / 19-) en Tijucas; los Cines Canelinha (1956 / 19-) y Astória (1953 / 19--), en Canelinha; el Cine São João (196- / 1979) en São João Batista y; el Cine Lindoia (1954 / 19--), en Nova Trento. La hipótesis es que la implementación de este circuito es una manifestación cultural de la sociedad y las salas se pueden abordar como importantes marcadores de desarrollo regional. El análisis de la formación de este circuito revela un complejo proceso de desarrollo regional, con continuidades y discontinuidades históricas, resultado de múltiples determinaciones sobre la configuración regional. Metodológicamente, la investigación partió de la orden cercana, las salas de cine tomadas en su particularidad y, a partir de un análisis histórico de cada una, se llegó a las cuestiones de orden más amplio, es decir, las cuestiones de desarrollo regional. Las encuestas empíricas se analizaron a la luz de investigaciones históricas y teóricas en tres campos: el desarrollo regional de Santa Catarina, la geografía del cine y el debate sobre la relación entre cine, cultura y desarrollo.

Palabras clave: Desarrollo regional. Viejos cines callejeros. Vale do Rio Tijucas (Santa Catarina, Brasil).

\section{Introdução}

O Vale do Rio Tijucas está localizado no litoral centro-norte catarinense, faz parte da Associação dos Municípios da Grande Florianópolis e é conformado por 8 cidades: Tijucas, no Baixo Vale; Canelinha, São João Batista e Nova Trento no Médio Vale e; Leoberto Leal, Major Gercino, Angelina e Rancho Queimado no Alto Vale (ZANLUCA, 2015). Ao longo deste Vale, estiveram em funcionamento durante o século XX seis salas de cinema de rua. Foram elas os Cines Manoel Cruz (1926/193-) e 
Lohse (195-/19--) em Tijucas; os Cines Canelinha (1956/19--) e Astória (1953/19--), em Canelinha; o Cine São João (196-/1979) em São João Batista e; o Cine Lindoia (1954/19--), em Nova Trento.

A conquista do território do Vale remonta ao século $\mathrm{XVI}$, entretanto, a colonização efetiva ocorre no século XVII a partir da imigração açoriana, quando é constituído o território da Enseada das Garoupas, com sede na atual Porto Belo, da qual o Baixo e Médio Vale faziam parte. Os primeiros casais de açorianos chegam ao Vale em 1776, mas a Freguesia com denominação de São Sebastião da Foz do Rio Tijucas é criada apenas em 1848 e sua promoção à Vila ocorre em 1859, quando são incorporadas ao seu território as Freguesias de Porto Belo e São João do Alto Tijucas. O município foi delimitado em 1916 (CAMPOS, 1994). A Freguesia de São João foi fundada em 1838 no encontro dos rios Braço e Tijucas e, no mesmo ano, foi organizada ali a Colônia Nova Itália, representando o território do atual município de São João Batista, desmembrado de Tijucas enquanto município em 1958 (SÃO JOÃO BATISTA, 2017). A colonização efetiva do território de Nova Trento também ocorre com a fundação de uma Colônia de imigrantes italianos, em 1875. A entrada desses imigrantes não se dá através do Rio Tijucas, mas de uma estrada aberta a partir de Brusque, portanto, seu caminho é pelo Vale do Itajaí. A freguesia de Nova Trento foi criada em 1884 (NOVA TRENTO, 2014). Em 1962 foram desmembrados de Tijucas os municípios de Canelinha, Major Gercino e Leoberto Leal.

A cidade de Tijucas foi pioneira ao receber a implantação de um cinema em 1926, o Cine Theatro Manoel Cruz, sendo a única a apresentar uma sala durante as décadas de 1920 e 1930. A sétima arte adentrou o Vale a partir da década de 1950, quando se desenha um novo período de abertura e funcionamento simultâneo de cinemas em Canelinha, São João Batista e Nova Trento, bem como é implantada uma nova sala em Tijucas. Portanto, o desenvolvimento deste circuito de exibição fragmenta-se no espaço e no tempo em dois momentos. Nas duas primeiras décadas do século XX a cidade de Tijucas viveu uma ascendência econômica acelerada, porém passageira, vinculada ao movimento portuário de importação e exportação, quando é inaugurado o Cine Theatro Manoel Cruz, fruto do investimento de um comerciante local. Com a decadência dos capitais comerciais deflagrada pela grande crise mundial de 1929, a sala encerra suas atividades no final da década de 1930. A partir da década de 1950, a abertura das outras cinco salas de cinema que o Vale do Tijucas abrigou não está mais vinculada a uma expansão de investimento do capital comercial, mas a diferentes contextos socioeconômicos, históricos e territoriais.

A história de cada uma dessas salas expressa um aspecto importante para compreensão do desenvolvimento regional do Vale do Tijucas, e, inclusive, proporciona o alargamento desse entendimento. A análise da formação desse circuito exibidor revela um processo de desenvolvimento regional complexo, com continuidades e descontinuidades históricas, e resultado de múltiplas determinações concernentes à configuração regional: a base econômica, a infraestrutura de transportes, os caminhos da colonização europeia, a conexão da região com capitais regionais do estado (Brusque, Blumenau, Florianópolis), e, por fim, a geografia física do Vale, que tem o Rio Tijucas como elemento importante para a configuração territorial e, por conseguinte, para a morfologia urbana. 
O presente artigo parte de uma investigação sobre o circuito exibidor de cinemas de rua do Vale do Rio Tijucas, precisamente no Baixo e Médio Vale, questionando como aspectos relativos à abertura, ao funcionamento e ao fechamento dessas salas conectam-se com o processo de desenvolvimento regional deste território. Nossa hipótese é que a implantação deste circuito exibidor é manifestação cultural da sociedade e as salas podem ser abordadas na perspectiva de importantes marcadores do desenvolvimento regional, que, por sua vez, está atrelado às escalas estadual, nacional e internacional. Nesta medida, a compreensão do contexto socioespacial de inserção das salas de cinema nas cidades lança luz sobre o processo de desenvolvimento regional do Vale entre as décadas de 1920 e 1970.

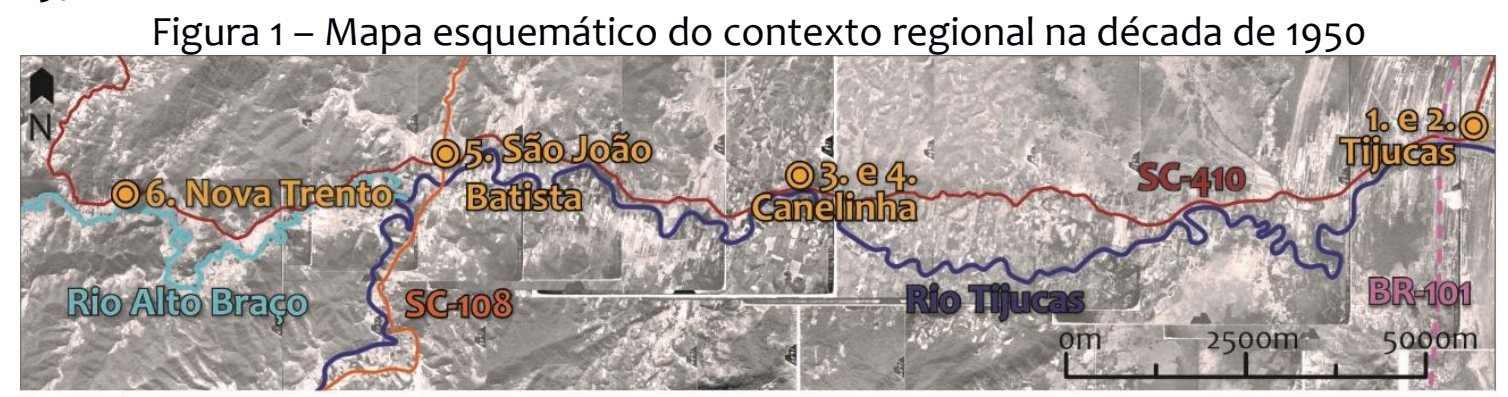

Legenda:

1.Cine Theatro Manoel Cruz 2.Cine Lohse 3.Cine Canelinha 4.Cine Astória 5.Cine São João 6.Cine Lindoia
$(1926$ - 193_)
(195_-19_) (1956-19_
$(1953-19$
(196_- 1979)
(1954-19_)

Fonte: Elaborado pelos autores sobre Mosaico de fotos aéreas do ano de 1957 (SANTA CATARINA, 1957).

Metodologicamente, a pesquisa iniciou da ordem próxima, as salas de cinema tomadas em sua particularidade e, a partir de uma análise histórica sobre cada uma delas, chegou-se às questões de ordem mais ampla, ou seja, as questões de desenvolvimento regional. Os caminhos da pesquisa envolveram levantamento documental, iconográfico e de informações verbais (entrevistas) sobre as salas material empírico que foi analisado e sintetizado à luz de pesquisas históricas e teóricas especialmente acerca de três campos: o desenvolvimento regional catarinense; a geografia do cinema, especificamente referente à esfera da exibição e; o debate acerca da relação entre cinema, cultura e desenvolvimento.

\section{Cinema, cultura e desenvolvimento regional em Santa Catarina: um campo teórico em formação}

A palavra cultura é tão polissêmica quanto o conceito de desenvolvimento é controverso, de forma que dissertar sobre as relações entre ambas exigiria um trabalho de delimitação conceitual que não caberia em um artigo. Certamente, este trabalho passaria pela obra de autores brasileiros como Celso Furtado (2012) e Renato Ortiz (2008). Se precisarmos o debate tratando do cinema enquanto expressão da cultura e, mais especificamente, da esfera da exibição cinematográfica (portanto, não da produção e tampouco da distribuição) e, também, esclarecendo que não trataremos do desenvolvimento de forma abstrata, mas do desenvolvimento regional, um breve estado da arte das pesquisas no Brasil torna-se 
palpável. Por fim, pode-se especificar ainda mais o debate, pois neste artigo abarcaremos o contexto catarinense.

De antemão, é preciso destacar que os principais interessados em pensar as relações entre cinema e desenvolvimento são pesquisadores do campo da cultura e da comunicação. Pesquisadores que costumam considerar a instância espacial em suas análises, como geógrafos, economistas ou cientistas sociais, têm se dedicado menos ao tema, de forma que a relação entre os termos cinema e desenvolvimento regional apresenta raros resultados se realizarmos uma busca rápida nos principais bancos de dados de pesquisa disponíveis no Brasil.

Em 1960, Paulo Emílio Salles Gomes de certa forma inaugura o debate mediante a publicação do texto clássico "Uma situação colonial?", em que trata a dominação cultural estadunidense como uma forma de colonialismo praticado contra o Brasil (GOMES, 1981). No entanto, a primeira denúncia pública desta situação cinematográfica colonial partiu de Humberto Mauro, em 1925: "Denunciava Mauro a falta de empenho das distribuidoras estrangeiras quando se trata de distribuir o filme nacional" (CAPOVILLA, 1963). Estes julgamentos intensificaram-se a partir dos anos 1960, com críticos reunidos em torno da Primeira Convenção Nacional da Crítica Cinematográfica realizada em São Paulo, na qual se propunha a "assumir atitude clara e definida face aos problemas que sufocam a nossa indústria, esforçando-se no sentido de libertar o Brasil de sua condição de país cinematograficamente subdesenvolvido" (CAPOVILLA, 1963). Para os intelectuais e artistas dos anos 1960/70, a identidade nacional e política do povo brasileiro, as raízes do Brasil e a ruptura com o subdesenvolvimento com base na intervenção do Estado eram questões centrais. Essas ideias foram aos poucos se diluindo sob efeito da ditadura, e, nos tempos atuais de mundialização do capital, elas voltam à tona (RIDENTI, 2000).

Estudos também se voltaram para entender porque o cinema brasileiro não se industrializou e quais os caminhos possíveis para fazê-lo, com destaque para o trabalho de Jean Claude Bernardet. Segundo Bernardet (2008), entre os anos 1950 e 1960 a historiografia clássica era principalmente voltada para a história dos filmes e dos cineastas; não fazia uma análise econômica, técnica e tampouco da legislação cinematográfica. No final dos anos 1980, a decadência do modelo de produção cinematográfico nacional causou também a crise deste discurso. Novos objetos e novos recortes foram colocados em pauta, com nomes como os de Anita Simis (1996), Eduardo Escorel (2005) e Carlos Augusto Calil (1996). Mesmo assim, até os anos 1990, poucas eram as análises econômicas do cinema brasileiro, menos ainda as geográficas seguindo o viés econômico/industrial. Entretanto, atualmente este campo vem se expandindo, principalmente mediante as explorações relacionadas à Economia Política das Comunicações, da Arte e da Cultura.

Ao se relacionar os campos do cinema e do desenvolvimento na contemporaneidade, três abordagens costumam aparecer. Primeiro, uma abordagem que problematiza o desenvolvimento econômico através do cinema este sendo enquadrado enquanto indústria ou economia criativa. Este conceito, que data da década de 1990, foi muito difundido pelo Ministério da Cultura no Brasil especialmente a partir do ano de 2012, quando foi criada uma Secretaria de Economia Criativa com o objetivo de fomentar a cultura enquanto eixo estratégico para o desenvolvimento nacional (BRASIL, 2011). Outra abordagem comum, e, de 
certa forma, decorrente da primeira, é aquela do campo de estudo das políticas culturais, que traz reflexões e estratégias sobre como desenvolver o cinema em uma perspectiva econômica e também política, enquanto expressão da cultura. Esta é a abordagem, por exemplo, que emana dos programas de cultura e desenvolvimento da UNESCO (2013). Por fim, tem-se os estudos do campo da economia política da cultura, que promovem análises econômicas da indústria cinematográfica. Aqui, tem-se como referência os trabalhos recentes de Almeida e Butcher (2003), Autran (2004) e Meleiro (2009).

Entretanto, nessas análises provindas do campo da comunicação, em geral a esfera da produção tem destaque em detrimento à distribuição e à exibição. Esta é uma tendência apontada por Autran (2004) como uma das maiores limitações do pensamento cinematográfico brasileiro: entender a indústria como produção desarticulada da distribuição e da exibição. Encontramos poucos estudos realizados no Brasil acerca da organização espacial do parque exibidor nacional, do ponto de vista intra-urbano e também econômico-industrial, tais como os de Gatti (2005) e Silva (2010).

O campo da Geografia do Cinema, onde o presente escrito se insere, é mais desenvolvido no sentido das análises fílmicas, ou seja, da pesquisa geográfica das imagens, do que na direção de outros temas como geopolítica, políticas culturais, globalização e indústria cultural (LUKINBEAL; ZIMMERMANN, 2006; MOREIRA; 2011). Dentro deste campo, Pozzo (2015), na tese "Uma geografia do cinema: bloqueios internacionais, contradições internas" realizou uma investigação geográfica sobre as formas de organização espacial da indústria cinematográfica brasileira (produção, distribuição e exibição). Neste trabalho e também em Pozzo (2020), focado na esfera da exibição, acionando o conceito de rede urbana como conector da escala intra-urbana com a escala regional, a autora argumenta que, historicamente, entre os dois momentos de ápice do número de salas de cinema no Brasil (no ano de 2018 o número de salas de exibição em território nacional ultrapassou de forma inédita o recorde de 1975, fixado em 3276 salas, chegando ao número de 3347), há dois movimentos. Um movimento em escala regional: do interior para o litoral e das cidades pequenas para as grandes. Outro movimento, em escala intra-urbana: das ruas dos centros tradicionais para os shopping centers. Como tendência contemporânea, identificou que, nos últimos anos, esse padrão vem se alterando: as salas reaparecem no interior, associadas à emergência nas cidades médias na rede urbana nacional, e também nas ruas. Estes trabalhos possivelmente sejam precursores em associar diretamente as salas de cinema e o desenvolvimento regional brasileiro:

Ao longo destas quatro décadas, demarcou-se o movimento das salas das cidades pequenas do interior para as grandes cidades do litoral. Do ponto de vista regional, o mapa de localização geográfica das salas acompanha o desenvolvimento e as desigualdades brasileiras. O movimento no sentido de uma concentração deu-se de oeste para leste e de norte para sul. Em 2018, quase 70\% das salas de exibição localizavam-se nas regiões Sul e Sudeste e, além disso, nestas regiões estão mais bem distribuídas no território dos estados. [...] Estando a rede urbana brasileira assentada sobre nossa formação socioespacial, em última análise, o desenvolvimento do cinema brasileiro, no que concerne ao parque 
exibidor, passa pela questão do desenvolvimento regional e urbano. (POZZO, 2020, p. 64).

Se há um hiato na produção científica sobre cinema e desenvolvimento regional, há uma tradição de estudos que irá relacionar as salas de cinema à modernidade urbano-industrial, realizando análises especialmente intra-urbanas. Nestes estudos, não aparece uma discussão sobre desenvolvimento, mas sobre modernidade, conceito que estabelece uma ponte com o desenvolvimento especialmente quando trabalhado a partir de sua dimensão econômica, enquanto modernização (BERMAN, 2009). Como afirma Pozzo (2020, p. 59): "As relações entre cidade e cinema marcam a essência desta arte. $O$ cinema surge para mostrar as novas experiências da modernidade urbano-industrial e, ao mesmo tempo, é produto desta". Neste âmbito, são muitos os trabalhos realizados no Brasil: Vieira e Pereira (1982), Gonzaga (1996), Charney e Schwartz (2001), Pinheiro e Fischer (2008), Stefani (2009), Ferraz (2009) etc. Em relação especificamente ao contexto catarinense tem-se os trabalhos de Munarim (2009), Bona (2009), Pozzo (2017), Müller e Pozzo (2017), Batista, Candeia e Dallabrida (2017) e Rambo et al. (2019) etc.

Estes últimos trabalhos apontam que as primeiras das aproximadamente 200 salas de cinema de rua fixas de Santa Catarina foram instaladas na década de 1900 na vertente atlântica do território. Seguindo a acepção de Berman (2009), Rambo et al. (2019) argumentam que o cinema ofertou aos catarinenses imagens primordiais da modernidade, aliando modernização (produção material, industrial) e modernismo (superestrutura, expressão da cultura):

\footnotetext{
No estado como um todo, a nova paisagem urbana na qual tem lugar a vida moderna começa a se formar nas cidades com maior relevância comercial (tal como Florianópolis, Lages, Laguna ou Blumenau) na passagem do século XIX para o XX e, nas demais, ao longo da primeira metade do século passado. Nesta nova paisagem, as salas de cinema são pontos focais, pois expressam uma combinação completa dos atributos da modernidade. (RAMBO et al., 2019).
}

Rambo et al. (2019) também promovem uma reflexão acerca do cinema e do desenvolvimento regional catarinense, argumentando que:

\footnotetext{
O surgimento temporal das salas se dá em paralelo ao desenvolvimento econômico das regiões. Inicialmente, há um investimento nas cidades litorâneas em que há maior densidade populacional e capital baseado no comércio. Mais tarde, os cinemas começam a aparecer em polos com base industrial, como Joinville, e, por último, a modernidade do cinema adentra o estado e populariza-se na economia agropecuária do planalto e do oeste catarinense.
}

Nesta linha, Müller e Pozzo (2017) também buscaram empreender uma análise do circuito exibidor de cinema considerando o desenvolvimento regional do Vale do Itajaí, notando o protagonismo deste onde, mesmo sendo de colonização mais recente que a grande Florianópolis, o sul catarinense e o planalto serrano, a presença do cinema mostrou-se numerosa e precoce, especialmente em Blumenau. As autoras destacam a compreensão do espaço regional como ponto fundamental para o entendimento do acesso ao cinema. No contexto de Blumenau, apontam 
que a popularização do cinema ocorre mediante parceria com as indústrias, que facilitavam o acesso a seus funcionários. Ao mesmo tempo, habitantes de outras cidades do Vale tinham a oportunidade de frequentar os cinemas de Blumenau graças a presença de ferrovias que faziam a ligação entre elas.

À luz deste campo teórico e empírico em formação, o presente trabalho busca contribuir com o debate e seu aprofundamento, objetivando compreender a inserção dos municípios do Vale do Rio Tijucas neste contexto.

\section{Décadas de 1920-1930: o Cine Theatro Manoel Cruz e a economia comercial portuária}

A primeira sala de cinema implantada no Vale do Rio Tijucas foi o Cine Theatro Manoel Cruz, na Rua Coronel Gallotti, na cidade de Tijucas, em 1926. Seu proprietário, Manoel Miranda da Cruz Sobrinho, nasceu em Negreiros, Portugal, em 1872, e migrou para Tijucas em 1888 estimulado por seu tio e padrinho, Manoel Miranda da Cruz, vigário da cidade. Antes de inaugurar o cinema, Manoel Cruz serviu à tradicional família Gallotti em seus negócios comerciais de cabotagem, plantações e também como contador, e trabalhou como comerciante varejista e jornalista (CAMPOS; BARENTIN, 1994).

Figura 2 - Cine Theatro Manoel Cruz na década de 1930.

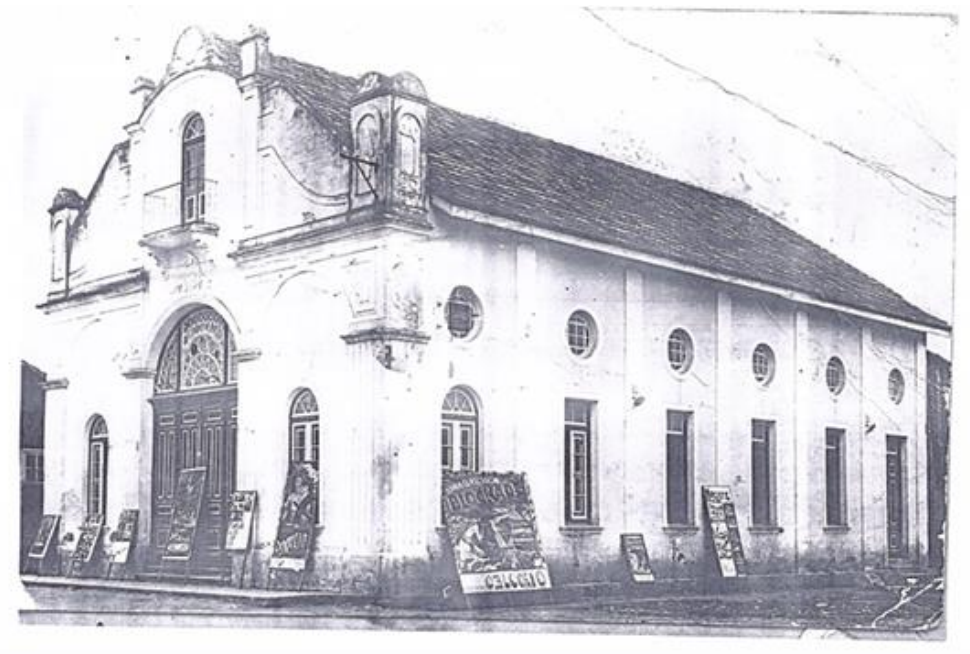

Fonte: Arquivo pessoal de Patrícia Terra Nova.

O desenvolvimento de Tijucas se deu a partir da economia extrativista, iniciada em meados do século XVIII, o que fez com que o povoamento se proliferasse junto às margens da foz do rio que nomeia a cidade (ANJOS, 2009). Além disso, ao longo do tempo, o território colonizado primeiramente por açorianos e posteriormente por italianos, começou a especializar-se na economia agrícola e pastoril, aperfeiçoando-se também na área da navegação, criando interrelações portuárias importantes. Desta forma, o município cresceu e alcançou seu auge populacional e econômico no início do século $X X$, com mais de cem embarcações em sua frota e elevada diversidade cultural, proveniente do intercâmbio comercial com grandes centros (ANJOS, 2009). Tiago Lessa de 
Miranda, museólogo responsável pelo Museu de Tijucas, afirma em entrevista que a cidade começa a demonstrar sinais de desenvolvimento econômico comercial no final do século XIX, e atrai empreendedores de outras localidades para ali se estabelecerem. É o caso de Benjamin Gallotti, que logo percebe uma oportunidade de investimento junto ao comércio varejista, já que até o momento Tijucas encontrava-se muito dependente de Florianópolis para suprir suas necessidades. Gallotti abre uma loja de secos e molhados comercializando inicialmente artigos têxteis consignados da Casa Hoepcke de Florianópolis, mas que prospera velozmente. Após a morte de Benjamin Gallotti, Manoel Cruz se estabelece por conta própria ${ }^{1}$. Contribuiu com o contexto de desenvolvimento da cidade ajudando a implantar a rede de luz elétrica e promovendo a abertura de estradas no interior. Possuiu também uma tipografia e uma papelaria, e auxiliou na implantação do Colégio Espírito Santo (CAMPOS; BARENTIN, 1994).

Em 1925, com auxílio do marceneiro alemão Ernesto Kesser, constrói a edificação do Cine Theatro Manoel Cruz, inaugurada em 06 de janeiro de 1926. Campos e Barentim (1994) relatam que Cruz já possuía um cinema mudo em 1915, porém em outras dependências. Como tinha sua própria tipografia, foi com facilidade que fez circular o Jornal do Cine Theatro, dirigido por seu filho Sebastião, que também musicava os filmes mudos antes de 1932, data do início da projeção de películas sonoras. Segundo os autores: "ali apresentavam-se os grandes experts da música, dança e as grandes companhias teatrais da época além de serem exibidas filmagens do cinema mudo nacional e mundial, visto que somente em 1932 iniciavam-se as exibições dos filmes falados" (CAMPOS; BARENTIM, 1994).

A edificação do Cine Theatro Manoel Cruz demarca, portanto, um contexto em que a cidade vive seu auge econômico, proveniente da navegação, agricultura e extrativismo vegetal. Segundo Campos e Barentim (1994) "Tijucas vivia realmente uma época de desenvolvimento, exportando por via marítima, madeira e sua produção agrícola, escoadas através de pequenos portos fluviais ao longo do rio Tijucas: a cidade era amarrada ao rio". A produção de todo Vale era comercializada regionalmente via porto, mas chegava até ele via rio. O Cine Theatro Manoel Cruz localiza-se na área central da cidade, às margens do Rio Tijucas. O museólogo Tiago Lessa de Miranda, relata que a cidade era profundamente atrelada ao rio. As próprias estradas de rodagem que ligavam o interior à centralidade municipal margeavam o corpo d'água. Ademais, foi a presença dele que incentivou o conquistador Sebastião Caboto a atracar em sua foz no século XVI, que inspirou a denominação do povoado, que escoou a produção local a partir da criação de portos fluviais impulsionando a economia. Foram estes portos que proporcionaram intercâmbio com grandes centros urbanos, possibilitando maior acesso à cultura moderna, além de serem responsáveis pelo assentamento linear da vila ao longo de suas margens e, por consequência, pela forma urbana atual de Tijucas (ANJOS,2009).

Além da vinculação ao rio, a localização da cidade em uma baía abrigada é fundamental para sua ocupação colonial. A conquista do litoral catarinense foi motivada inicialmente pela intenção de expansão territorial rumo à foz do Rio da

\footnotetext{
${ }^{1}$ Informação verbal. Entrevista com Tiago Lessa de Miranda, museólogo responsável pelo Museu de Tijucas, realizada pelos autores em março de 2020.
} 
Prata. Baías abrigadas e arroios eram considerados locais privilegiados para a ocupação portuguesa, em virtude de facilitarem a instalação de estruturas portuárias. O papel da economia portuária marítima foi de suma importância para o crescimento de regiões de povoamento açoriano, criando toda uma base comercial e infraestrutura urbana e de serviços para o atendimento das necessidades desta população. Este desenvolvimento acelera-se ainda mais com a introdução do comércio de importação e exportação, em que os comerciantes açorianos são substituídos por imigrantes de origem europeia, os quais modernizam e trazem uma variedade de artigos nunca antes comercializados nestes portos (BASTOS, 2000). Eram eles também que tomaram a frente em outros setores da economia, sendo responsáveis pela abertura de novos comércios, indústrias e também, salas de cinema. A expansão portuária de Tijucas no final do século XIX está diretamente relacionada a expansão da produção do Vale, associada às colônias italianas ali estabelecidas, e a necessidade de escoamento dessa produção.

A vinda crescente de europeus para a sede do município e seu interior no início do século XIX possibilitou a distribuição de sesmarias ao longo da margem, acentuando a evolução da área e aprimorando a economia extrativista, comercial e agrícola. Porém, neste cenário, ainda não havia estradas que favorecessem o tráfego para o escoamento da produção. Desta forma, o Rio Tijucas era utilizado para o transporte dos produtos, principalmente da madeira proveniente das serrarias no interior através de balsas, que comportavam de 50 a 100 dúzias de madeiras, as quais alcançavam 50 metros de comprimento. Estas viagens poderiam durar até uma semana, e demandavam o esforço de três a quatro balseiros que empurravam a embarcação com grandes varas. Foi por esta razão que as margens do rio foram cada vez mais ocupadas, com os comerciantes adentrando o território rio acima, na esperança de serem os primeiros a entrar em contato com os vendedores e assim, adquirirem os produtos com antecedência (ANJOS, 2009).

Com a popularização do transporte de carga fluvial, houve a criação de pequenos portos particulares das casas comerciais, com pontos de ancoragem considerados estratégicos nas margens do Rio Tijucas. Estando esta dinâmica consolidada, a atividade fluvial torna-se também marítima, criando relações mercantis com portos como os de Florianópolis, Paranaguá, Santos e Rio de Janeiro. Relata-se que as embarcações levavam produtos agrícolas como madeira, arroz, milho e açúcar, e retornavam com produtos normalmente não comercializados na cidade. A navegação marítima foi de extrema importância para o desenvolvimento municipal da época, pois criou oportunidades de trabalho nos diversos portos e possibilitou a abertura de casas comerciais com os mais variados produtos, além de armazéns para a estocagem de mercadorias.

Entender essa vinculação da cidade com o porto e o rio é fundamental para compreender a decadência vivida por ela entre as décadas de 1930 e 1960. A grande crise mundial de 1929 afeta especialmente as cidades portuárias brasileiras que têm seus portos instalados em baías abrigadas, como são os casos de Laguna, Florianópolis ou Tijucas, no estado de Santa Catarina. Isso porque essas cidades, além de sofrerem as consequências da crise comercial, não conseguem se reinventar no sentido de absorver as transformações no transporte marítimo, com grandes navios que exigiam calados cada vez maiores. A navegação fluvial é prejudicada pelo assoreamento do rio, e não encontra mais espaço no contexto de 
valorização do modal rodoviário, que vai culminar com a instalação da BR 101 cortando, redesenhando e redirecionando a cidade a partir dos anos 1960. As rodovias alteram o intercâmbio regional de mercadorias, e as antigas cidades portuárias perdem ainda mais sua força. Tiago Lessa de Miranda afirma que no final dos anos 1960, com a transposição da BR-101, o desenho urbano sofreu forte impacto, pois a obra foi o motivo da demolição de edificações importantes, como a residência do Sr. Manoel Cruz, proprietário do cinema, que situavam-se em todo o eixo onde hoje se encontra a $B R$, além de causar um rompimento do tecido da cidade.

De uma economia extrativista, agrária e comercial, na década de 1930 o Vale do Tijucas passa a direcionar uma economia manufatureira que se desenvolverá industrialmente a partir dos anos 1970 no ramo calçadista em São João Batista e cerâmico em Canelinha e Tijucas. Neste cenário de crise econômica da década de 1930, a firma de Manoel Cruz encontra seu fim e com ela seus negócios associados, dentre eles o cinema. No ano de 1998, a edificação foi tombada e restaurada pelo Estado de Santa Catarina, e na primeira década do século XXI, chegou a abrigar usos culturais e populares. Foi a partir de 2011, que o estado de conservação da edificação começou a declinar com rapidez. No final deste ano ocorre um incêndio, causado acidentalmente por pessoas que usavam o espaço como abrigo. $\mathrm{O}$ fogo consumiu a área do palco e do fundo do Cine Theatro, fazendo com que seu interior ficasse vulnerável à intempéries ${ }^{2}$.

Assim, o arruinamento da edificação tornou-se exponencial: no ano de 2016, grande parte da madeira do interior da sala é roubada, por ter alto valor comercial; em 2017, mais da metade da cobertura desaba, em 2018, a parte superior esquerda da fachada entra em colapso; em 2019, este segmento acaba por desabar, e; em março de 2020, toda a parte superior da fachada desmorona. Atualmente, a ruína é de acesso restrito, está cercada, e é proibida a passagem de veículos pesados nas proximidades devido a vibração que estes causam, medidas determinadas pela Defesa Civil por conta do risco de desabamento 3 .

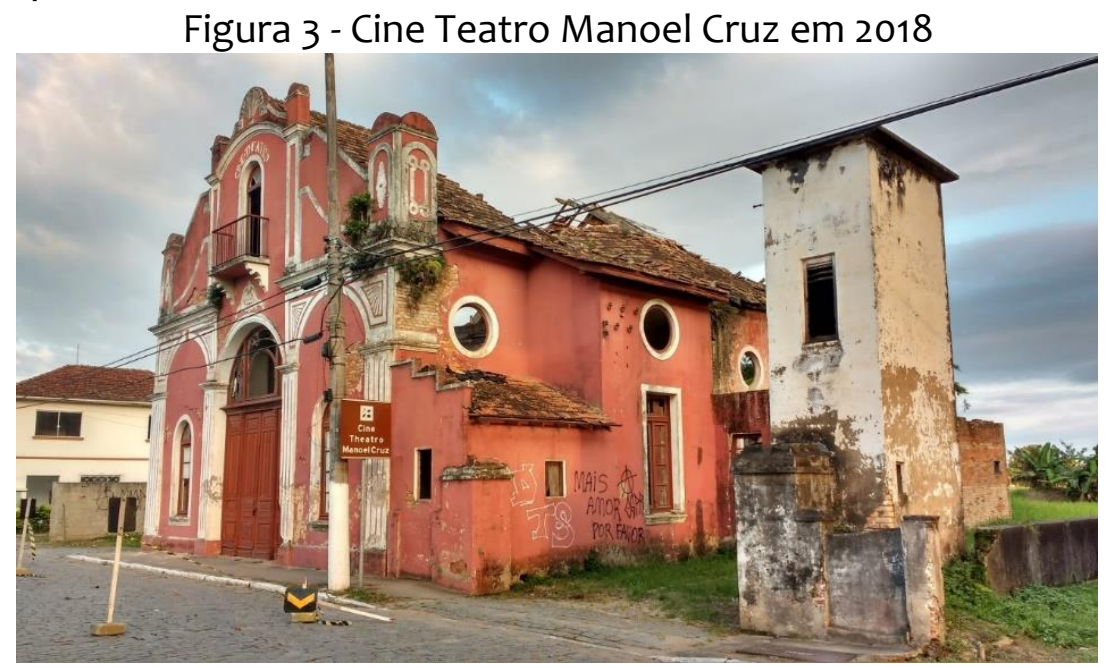

Fonte: Acervo dos autores.

\footnotetext{
${ }^{2}$ Informação verbal. Entrevista com Tiago Lessa de Miranda, museólogo responsável pelo Museu de Tijucas, realizada pelos autores em março de 2020.

3 Informação verbal. Entrevista com Tiago Lessa de Miranda, museólogo responsável pelo Museu de Tijucas, realizada pelos autores em março de 2020.
} 


\section{Décadas de 1940-1970: novos cinemas, outros aspectos do desenvolvimento regional}

Com a falência do Cine Theatro Manoel Cruz, a cidade de Tijucas fica sem acesso à sétima arte até a chegada de Artur Lohse, nascido em 1909 na cidade de Blumenau. Em meados de 1948, Lohse instala uma sala de exibição improvisada no salão do Clube 4 de Maio, e a denomina de Cine Tijucas. A atividade funcionou no local até o dia 18 de janeiro de 1951, quando a edificação do clube, datada de 1892, é arruinada por conta de um incêndio (O ESTADO, 1951). Com a perda, o Artur instala o cinema em um galpão de madeira, nos fundos do terreno onde posteriormente é edificado o Cine Lohse. Relata-se que "Embora longe dos atuais padrões de conforto oferecidos pelas grandes casas de espetáculos, as instalações pioneiras agradavam seus frequentadores, pois procuravam apenas deliciar-se com as magníficas produções ali exibidas" (CAMPOS; BARENTIN, 1994). Por outro lado, quando se trata da nova edificação, alega-se que o espaço criou um ambiente para a elite e habitués, com piso vermelho encerado, cortinas de veludo na cor grená e um alto hall, dando a ideia de luxo e elegância. Neste novo espaço, além da exibição de películas, frequentemente eram realizados concursos de beleza, com a presença da alta sociedade tijuquense. Localizava-se na Rua Coronel Buchelle, e contemplava 350 lugares. Atualmente, a edificação é ocupada por uma igreja pentecostal.

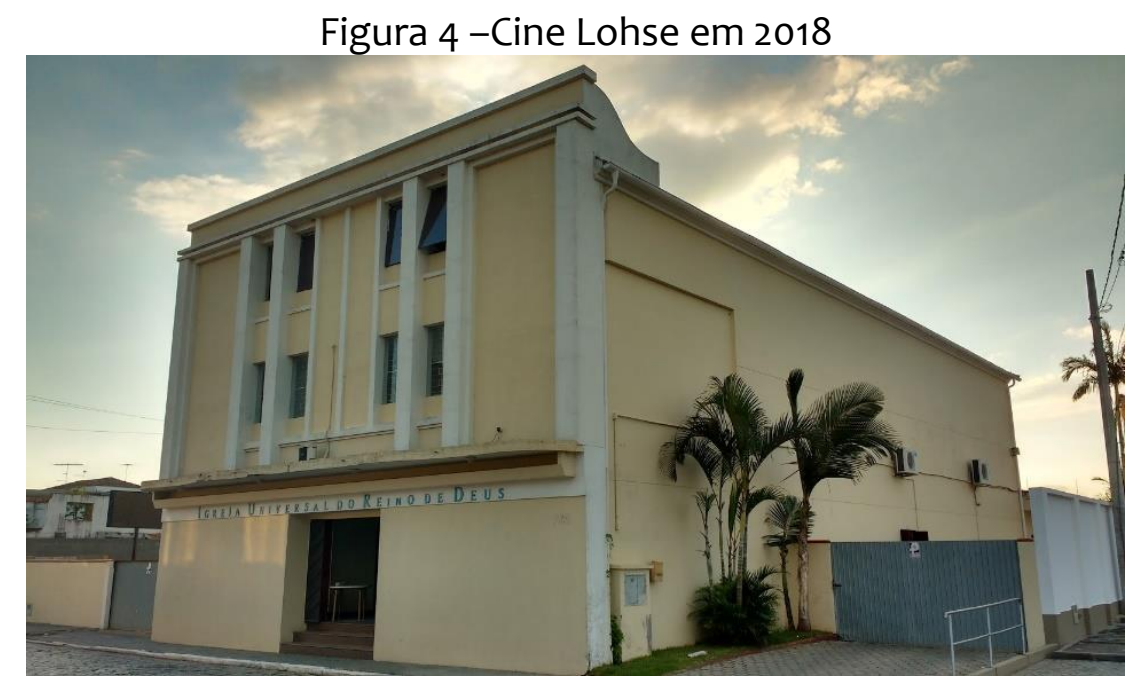

Fonte: Acervo dos autores

Antes de deslocar-se para Tijucas, Lohse já possuía uma sala de cinema em sua cidade natal, o Cine Garcia, em parceria com Carlos Zuege. É um cinema que entra em operação no salão de Hermann Hindkeldey em 1941, e tem sua própria edificação inaugurada em 1944 (MÜLLER; POZZO, 2017). A sociedade funciona até o ano de 1948, quando Artur decide sair de Blumenau e dirigir-se a Tijucas. Além do Cine Garcia, em Blumenau e do Cine Lohse em Tijucas, Artur possuiu também uma sala de cinema na cidade de Canelinha, inaugurada em 1956, com aproximadamente 120 lugares. Há registro da existência de outro cinema na cidade de Canelinha, o Cine Astória, inaugurado em 1953, contando com 500 lugares (CINEMAFALDA, 2013). 
A implantação do Cine Lohse de Tijucas e do Cine Canelinha de Canelinha por Artur Lohse são marcadores do intercâmbio regional existente entre o Vale do Rio Tijucas e o Vale do Itajaí. Na obra "Vida Regional em Santa Catarina” (1966), o geógrafo Armen Mamigonian reconhece a área sub-regional de Brusque, e as áreas regionais de Blumenau e Florianópolis como polarizadoras dos municípios do Vale do Rio Tijucas.

Figura 5 - Zona de Influência das Cidades - Santa Catarina - 1966

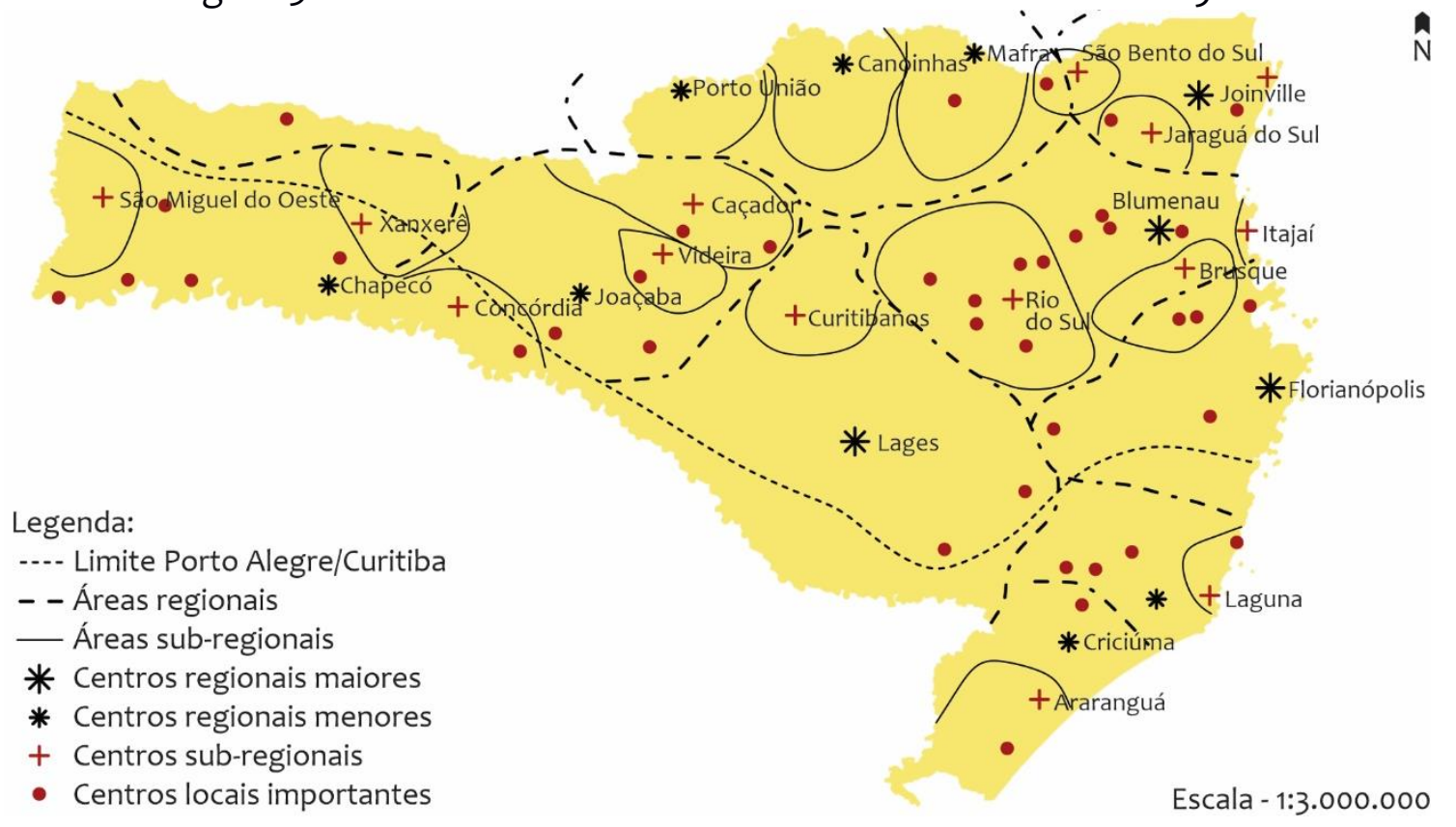

Fonte: Mamigonian, 1966. Adaptado pelos autores.

Essa polarização de Blumenau e Florianópolis são perceptíveis também através da história do Cine São João, de São João Batista. O desenvolvimento moderno do Vale do Rio Tijucas se dá a partir do século XIX, com o povoamento europeu adentrando o território tanto pela vertente terrestre, proveniente de Brusque e Blumenau, quanto pela litorânea, que penetra o Vale através do Rio Tijucas. Esta movimentação ao longo do estado propiciou a criação de caminhos usuais, que atualmente se traduzem em estradas e rodovias, testemunhas do então fluxo colonizador. O percurso desde Blumenau, passando por Brusque e adentrando o Vale a partir de Nova Trento configurou-se como a atual SC 108. Ao longo do Rio Tijucas, desenvolveu-se SC 410, ligando Tijucas à Nova Trento. São João Batista é uma cidade que atualmente se encontra no entroncamento da SC $410 \mathrm{com}$ a SC 108, rodovias estaduais na atualidade, que tem seu traçado proveniente dos caminhos abertos pela colonização, ilustrados abaixo. 
Figura 6: Roteiro das colonizações alemã e italiana no nordeste de Santa Catarina Colonização Alemã

Colonização Italiana

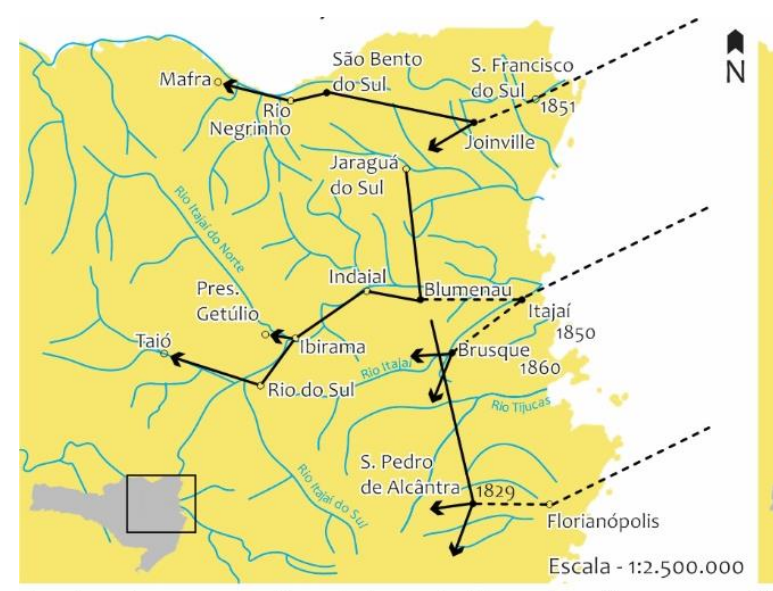

Legenda: -.--.- Caminhos de Penetração $\longleftarrow$ Caminhos de Expansão

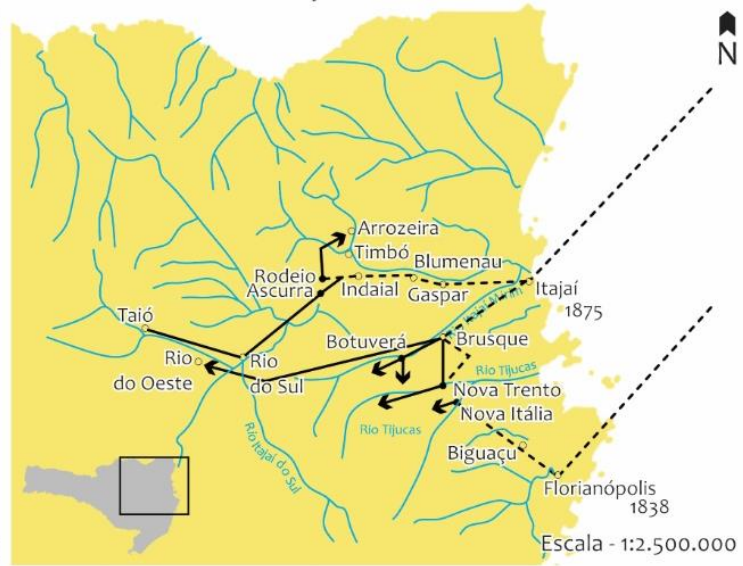

Fonte: Santa Catarina, 1958. Adaptado pelos autores.

Figura 7: Distribuição rodoviária do nordeste de Santa Catarina e conexões - 1958

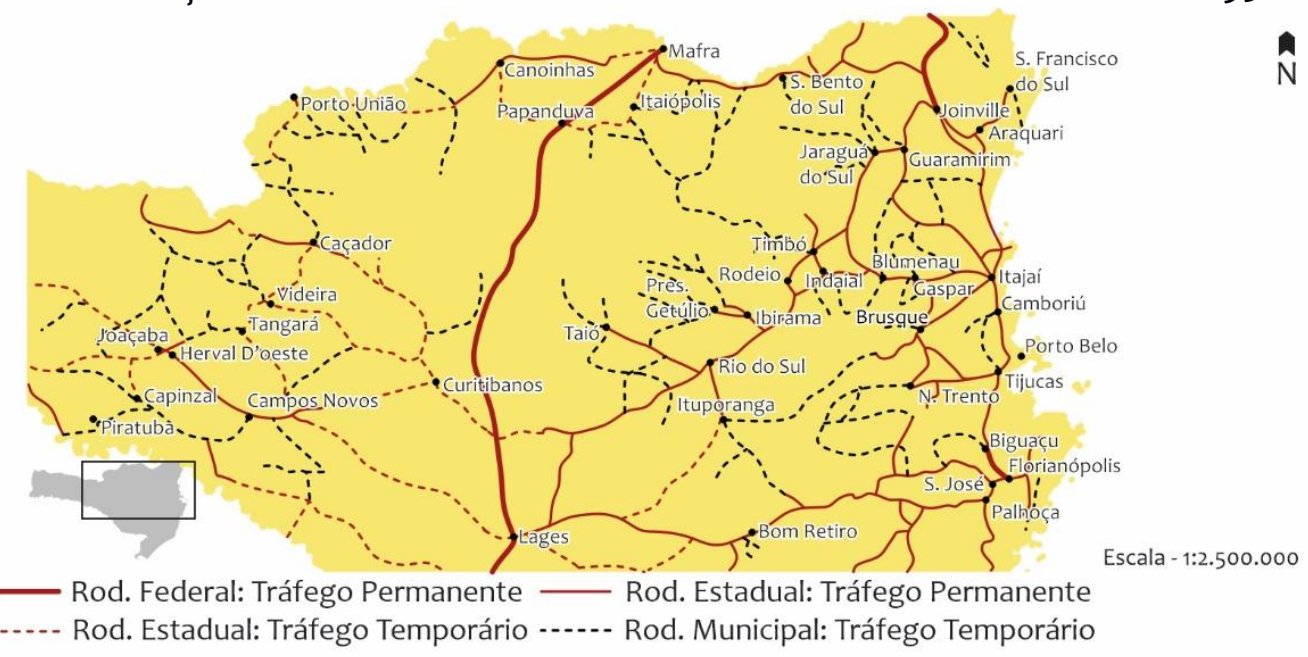

Fonte: Santa Catarina, 1958. Adaptado pelos autores.

Em São João Batista, Leopoldo João Campos implanta, na década de 1960, o Cine São João. Leopoldo e seu irmão Pedro eram dentistas, provenientes de Santo Amaro da Imperatriz, e se deslocam para São João Batista em fins da década de 1950. Após alguns anos, Pedro vai para a cidade de Alfredo Wagner, onde com auxílio de seu outro irmão, José, abre uma pequena sala de cinema. É então que, incentivado pelos irmãos mais velhos, Leopoldo decide inaugurar o Cine São João, exibindo as mesmas películas utilizadas no empreendimento familiar existente em Alfredo Wagner. Inicialmente, o cinema acontecia no piso superior da residência de Leopoldo, e foi somente com a popularização da atividade que se criou um espaço maior ao lado de sua casa, com maquinário adquirido na cidade de Curitiba, e películas alugadas a partir de parcerias com outras salas da região. A sala de cinema possuía por volta de 500 poltronas de madeira envernizada, uma tela de projeção de $10 \times 4 \mathrm{~m}$ e, além da atividade exibidora, era utilizado para peças teatrais e formaturas. 
Figura 8: Cine São João

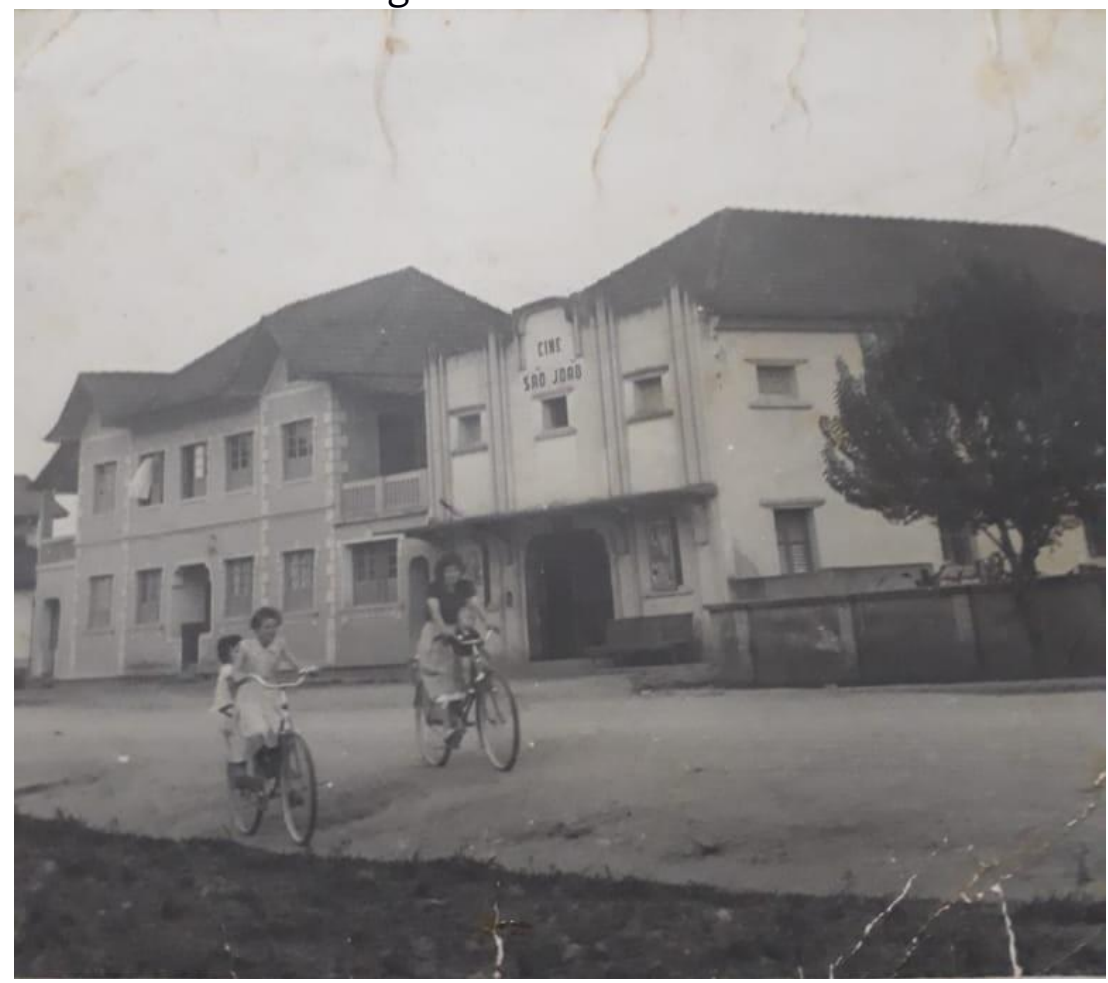

Fonte: Farias, 2019

O Cine São João ficava localizado na Rua Getúlio Vargas, uma das mais importantes da cidade, e funcionou até o ano de 1979.

Adentrando-se o Vale, existiu em Nova Trento, o Cine Lindóia. Fundado em 1954 pelo imigrante italiano Marçal Voltolini, possuía 162 lugares, e localizava-se na Rua Marechal Deodoro. A história desse cinema revela aspectos relativos à história da imigração europeia do Médio Vale, bem como, novamente, as conexões entre o Vale do Rio Tijucas e o do Itajaí. A família de Marçal, como a massiva população da cidade, é proveniente da Itália. Mais especificamente, da comuna de Borgo Valsugana, de onde seu bisavô, Antonio Voltolini parte com a família em 26/12/1875, com destino ao porto de Itajaí. A viagem teve duração de setenta dias, e passou pelo porto do Rio de Janeiro e de Desterro, onde a família desembarca e se encaminha à colônia de Itajaí, para depois deslocar-se para Brusque e finalmente, assenta-se na região hoje conhecida por Nova Trento (VOLTOLINI, 2012).

Esta fotografia dos trabalhos de campo do IBGE, de 1953, mostra Nova Trento, então cidade mais importante do Vale em termos populacionais (SANTA CATARINA, 1958). De fato, é difícil relacionar o contexto das cidades do Médio Vale com os atributos da modernidade expressos nos trabalhos que analisam a emergência dos cinemas nas cidades brasileiras no século XX. Ao contrário, é a ruralidade que se destaca, indicando um novo campo de pesquisa relativo especificamente ao surgimento dos cinemas no estado de Santa Catarina e sua realidade de predominância de pequenas cidades, e, durante todo o século $X X, a$ ausência mesmo de uma capital que polarizasse todo o território: a associação entre as salas de cinema e o mundo rural. 
Cinemas de rua ao longo do Vale do Rio Tijucas (SC): expressões da cultura e marcadores do desenvolvimento regional 
Figura 9: Vista de Nova Trento em 1953

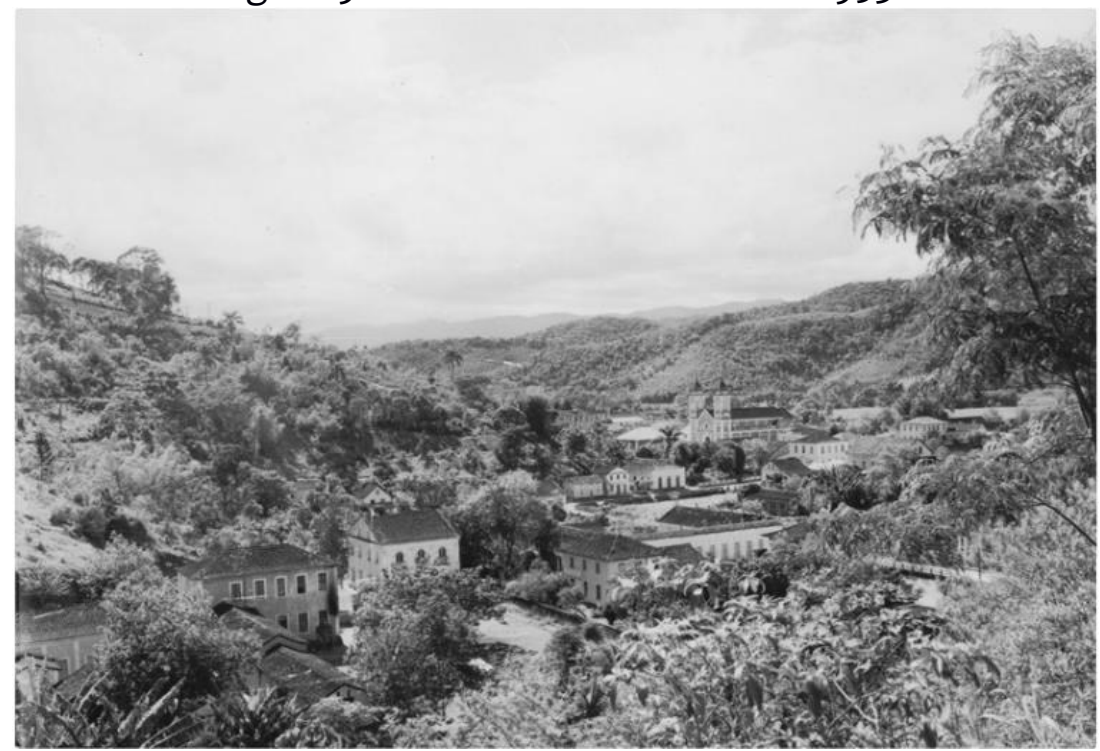

Fonte: IBGE, 1953

Marçal implanta o cinema em uma casa tradicional da cidade, chamada Casa Salamanca, uma das primeiras edificações construídas pelos imigrantes da região, a qual abrigou variados usos, e, inclusive, serviu de espaço para a realização de catequese por Madre Paulina (NOVA TRENTO, 2014). Atualmente, a Casa Salamanca atende à usos comerciais como Lotérica e Loja de vestuário.

Figura 10: Casa Salamanca atualmente

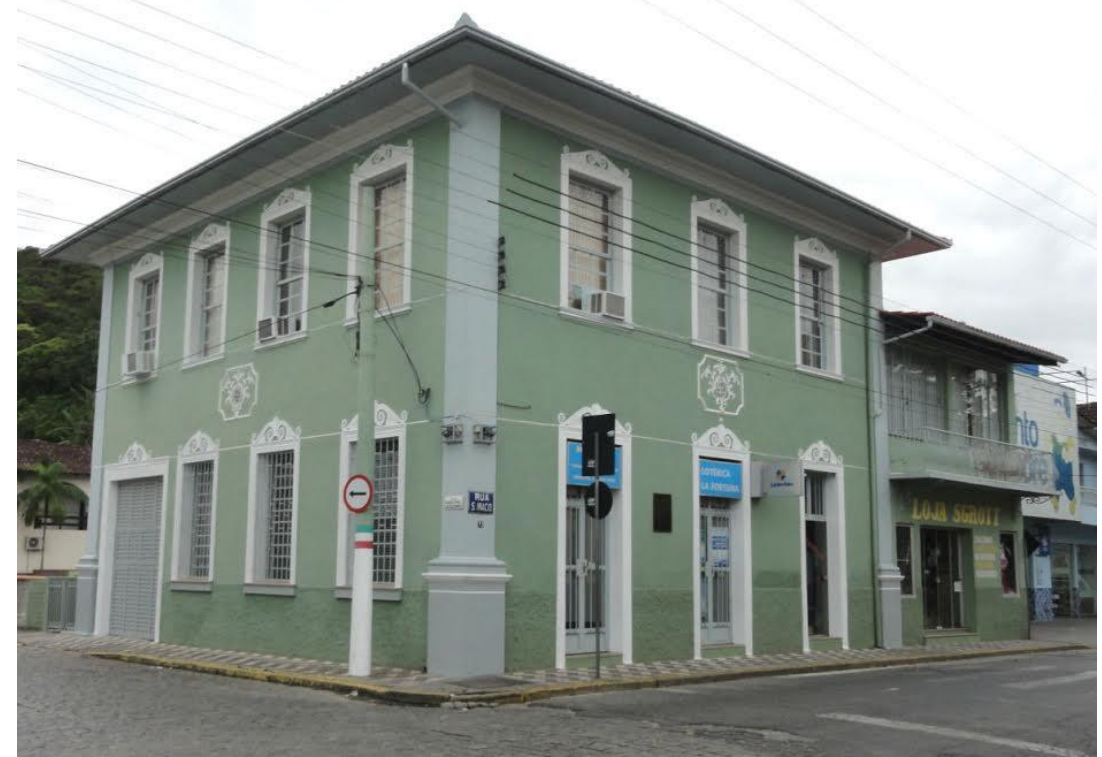

Fonte: Nova Trento, 2014.

\section{Considerações Finais}

Este escrito foi norteado pelo problema de investigação de compreender como as esferas do desenvolvimento regional e da cultura, mais especificamente o cinema, se combinaram no contexto específico do Vale do Rio Tijucas ao longo da 
história. Neste caminho, mais do que perceber que o estabelecimento das salas confirmaria as teses sobre o desenvolvimento regional dos vales atlânticos catarinenses, a investigação histórica a partir destes objetos do território iluminou aspectos referentes à complexidade dos processos.

A análise do desenvolvimento regional dos vales atlânticos catarinenses tende, em geral, a uma interpretação que aborda a incursão a partir da foz adentrando o território, de forma linear. Nossa pesquisa revelou as descontinuidades desse processo, perceptíveis pelo próprio histórico da divisão política-administrativa regional, proporcionada pela ligação do Vale, pelo interior, com as prósperas colônias do Vale do Itajaí e, pelo litoral, também por Florianópolis. Entende-se, desta forma, que mesmo Tijucas tendo sido a origem políticoadministrativa das cidades, ela divide a polarização urbana com estes outros centros, de diversas formas.

Portanto, para além da tese do desenvolvimento que adentra o Vale (neste caso, através do curso do rio e do caminho da atual SC 410) a partir da cidade poloportuária, Tijucas, percebe-se que há outros caminhos para o desenvolvimento. Há um claro caminho que parte da região nordeste do estado, fruto da conexão do Vale do Tijucas com o Vale do Itajaí via Brusque, através da atual SC 108. Em adição, identifica-se também que os núcleos urbanos do Vale do Tijucas foram polarizados por outras cidades para além da sede (São Sebastião, hoje Tijucas), como Brusque, Blumenau e Florianópolis. Além disso, o fato de o Alto Vale não apresentar cinemas explica-se em função desta região estar relacionada à dinâmica do Planalto Serrano catarinense, portanto, pouco urbanizada.

As salas de cinema se colocaram nas cidades como imponentes pontos nodais, polos de movimentação noturna e vida urbana importantes para o desenvolvimento econômico e sociocultural dos municípios. Neste âmbito, percebese que a presença do Cine Theatro Manoel Cruz e o Cine Lohse na cidade de Tijucas são expressões de cosmopolitismo e urbanidade, sendo sua própria arquitetura mais suntuosa, respectivamente eclética e art déco, um testemunho desse fato. Já as demais salas eram muito mais simples, pelo fato de terem sido edificadas mais tarde, em um diferente cenário econômico e atreladas a contextos urbanos ligados à economias rurais. Ao se estabelecerem em centros minimamente urbanizados, recebiam público não apenas do município, mas também dos territórios adjacentes. Este fato contribui para a formação de malhas de acesso à sétima arte, proporcionando à população local um rico intercâmbio cultural entre os povoamentos, além de fomentar a economia regional, e de facilitar o acesso à atividade, que se torna mais abrangente. Constata-se assim, que entender o alcance das salas de cinema é uma tarefa complexa, pois para tanto é necessário apreender o território, o desenvolvimento, a economia, as conexões urbanas e a geografia particular de cada região.

Ao percorrer este histórico, é inevitável questionar-se sobre o porquê de uma região que já contou com seis salas de cinema de rua, hoje não apresentar nenhuma. Observa-se que o estado de Santa Catarina, como um todo, sofreu com o movimento nacional de fechamento das salas de cinema de rua especialmente no início dos anos 1990, de forma que, atualmente, grande parte das cidades que tinham o cinema como um lazer tradicional, perdeu este hábito cotidiano. Desde a metade dos anos 1970, houve uma queda no número de salas de exibição instaladas 
em nosso país. Esta queda, além de estar relacionada à expansão da televisão, está também associada ao surgimento de novos padrões tecnológicos na exibição e de organização comercial, para os quais poucos empresários brasileiros estavam preparados para se adaptar. A partir dos anos 1990 ocorre a entrada de grandes empresas estrangeiras no segmento de exibição no Brasil que introduzem em nossa realidade o conceito de multiplex: atualmente $90 \%$ das salas de cinema no Brasil estão instaladas em shopping centers, seguindo os padrões técnicos ditados por Hollywood. Esta imposição tecnológica inaugurou um processo de valorização crescente dos aparatos técnicos das salas, e tornou sua modernização urgente. A concentração nos pontos mais lucrativos do território nacional é um dos principais motivos que podem ser elencados para explicar a diminuição do número de salas de cinema no Brasil, e o desaparecimento das salas das cidades em questão. Com o fechamento dos cinemas de rua, os centros tradicionais das cidades perderam movimento noturno e viram enfraquecer seu caráter de lugar de encontro e sociabilidade urbana.

Entretanto, o esgotamento do modelo de salas de rua tem um viés social, que vai além desta questão tecnológica. Este modelo vai ao encontro de uma das grandes fantasias da primeira fase da modernidade: a rua. Os investimentos urbanos nas cidades brasileiras, especialmente na segunda metade do século XX, foram destinados à autopistas, estreitamente ligadas à outras estruturas como os shopping centers, para onde os cinemas migraram. A partir daí, em poucas décadas, a rua, que sempre servira à expressão da modernidade, passa a simbolizar "tudo que havia de encardido, desordenado, apático, estagnado, gasto e obsoleto" (BERMAN, 2009, p. 301). Assim, relaciona-se também o esvaziamento das ruas com o fechamento das salas de cinema a elas ligadas.

Atualmente, os moradores do Vale do Rio Tijucas têm como salas mais próximas os multiplex do grupo Gracher (originário em Brusque na década de 1930) inseridos nas lojas de departamentos Havan das cidades de Brusque e Porto Belo.

\section{REFERÊNCIAS}

ANJOS, Manoel dos. Tijucas: um pouco de sua história. Tijucas: Telles, 2009.

BASTOS, José Messias. Urbanização, comércio e pequena produção mercantil pesqueira na Ilha de Santa Catarina. Ensaios sobre Santa Catarina. Florianópolis: Letras Contemporâneas, p. 127-40, 2000.

ALMEIDA, Paulo Sérgio; BUTCHER, Pedro. Cinema, desenvolvimento e mercado. São Paulo: Aeroplano, 2003.

AUTRAN, Arthur. O pensamento industrial cinematográfico brasileiro. Tese de Doutorado apresentado ao Programa de Pós-graduação em Multimeios, Instituto de Artes. Universidade Estadual de Campinas. Campinas, 2004.

BATISTA, Bhrenda Ketlyn; CANDEIA, Luís Eduardo; DALLABRIDA, Willian Sartor. Espaço e Cultura: as antigas salsa de cinema de rua de Santa Catarina. XV Simpurb Simpósio Nacional de Geografia Urbana. Salvador, 2017. Disponível em: 
Cinemas de rua ao longo do Vale do Rio Tijucas (SC): expressões da cultura e marcadores do desenvolvimento regional

<http://www.inscricoesxvsimpurb.ufba.br/modulos/consulta\&relatorio/rel_downloa d.asp?nome $=88499$. docx $>$.Acesso em 20/08/2020.

BERMAN, Marshall. Tudo que é sólido desmancha no ar. SP: Companhia das Letras, 2009.

BERNARDET, Jean-Claude. Historiografia clássica do cinema brasileiro: metodologia e pedagogia. São Paulo: Annablume, 2008.

BONA, Rafael Jose. Do Teatro Frohsinn aos cinemas do shopping: a história do cinema em Blumenau. In: REIS, Clóvis (Org.). Realidade regional em comunicação: perspectivas da comunicação no Vale do Itajaí. Blumenau: Edifurb, 2009.

BRASIL. Ministério da Cultura. Plano da Secretaria da Economia Criativa: políticas, diretrizes e ações, 2011 - 2014. Brasília, 2011. Disponível em:

$<$ http://www2.cultura.gov.br/site/wp-

content/uploads/2012/08/livro_web2edicao.pdf>. Acesso em 28/08/2020.

CALIL, Carlos Augusto. Cinema e Indústria. In: Xavier, Ismail (org.). 0 cinema no século. Rio de Janeiro: Imago, 1996.

CAMPOS, Ademar; BARENTIN, Leopoldo. Fatos e fotos da história tijuquense. Tijucas: 1994 .

CAPOVILLA, Maurice. Cinema nacional: problema que o governo tem que resolver. Jornal Última Hora. 30 de setembro de 1963. Fonte: Acervo de Livros e Documentos da Cinemateca Brasileira. Biblioteca Paulo Emílio Sales Gomes.

CINEMAFALDA. [Blog]. Relação de cinemas antigos de Rua do Brasil em atividade nos anos 1960. Tijucas. 2013. Disponível em: <

http://cinemafalda.blogspot.com/search?q=tijucas>. Acesso em 15/08/2020.

CHARNEY, Leo e SCHWARTZ, Vanessa R.(Org.). O cinema e a invenção da vida moderna. Tradução: Regina Thompson. São Paulo: Cosac \& Naify, 2001.

ESCOREL, Eduardo. Adivinhadores de água: pensando o cinema brasileiro. São Paulo: Cosac Naify, 2005.

FARIAS, Miriany. Cinema com 500 poltronas fez sucesso das décadas de 60 e 70 em São João Batista. O Município [Site de notícias]. 17/03/2019. Disponível em: < https://omunicipio.com.br/cinema-de-sao-joao-batista-fez-sucesso-nos-anos-6o-e70/>. Acesso em 28/08/2020.

FERRAZ, Talitah. Entre arquiteturas e imagens em movimento: cinemas, corporeidades e espectação cinematográfica na Tijuca. Logos 32. Ano 17, n.1, 2010. Disponível em: < https://www.epublicacoes.uerj.br/index.php/logos/article/view/549>. Acesso em 27/08/2020. 
FURTADO, Celso. Ensaios sobre cultura e o Ministério da Cultura. Rio de Janeiro: Contraponto, 2012.

GATTI, André Piero. Distribuição e exibição na indústria cinematográfica brasileira (1993 - 2003). Tese de Doutorado. Instituto de Artes da UNICAMP. Campinas - SP, 2005.

GOMES, Paulo Emílio. Uma situação colonial? In: Crítica de Cinema no Suplemento Literário. Rio de Janeiro: Paz e Terra, 1981.

GONZAGA, Alice. Palácios e Poeiras: 100 anos de cinema no Rio de Janeiro. Rio de Janeiro: Ministério da Cultura, Funarte, Record, 1996.

IBGE. Acervo dos Trabalhos de Campo. Tijucas [Fotografia]. 1953. Disponível em: < https://biblioteca.ibge.gov.br/>. Acesso em 20/08/2020.

LUKINBEAL, Chris; ZIMMERMANN, Stefan. Film Geography: a new subfield. Erdkunde, n. 60, 2006.

MAMIGONIAN, Armen. Vida Regional em Santa Catarina. In: Orientação. IGEO/USP, set.1966.

MELEIRO, Alessandra (Org.). Cinema e Economia Política. São Paulo: Escrituras, 2009.

MOREIRA, Tiago de Almeida. Geografia e Cinema no Brasil - revisão bibliográfica. 2011. Disponível em:

<https://periodicos.ufms.br/index.php/revgeo/article/view/1063/1188>. Acesso em 12/08/2020.

MULLER, Yasmin Lopes Muller; POZZO, Renata Rogowski. Cartografias do cinema: o protagonismo de Blumenau no contexto catarinense. XV Simpurb - Simpósio Nacional de Geografia Urbana. Salvador, 2017. Disponível em:

<http://www.inscricoesxvsimpurb.ufba.br/modulos/consulta\&relatorio/rel_downloa d.asp?nome $=88424$. docx $>$. Acesso em 20/08/2020.

MUNARIM, Ulisses. Arquitetura dos cinemas: um estudo da modernidade em Santa Catarina. Dissertação (Mestrado) - Universidade Federal de Santa Catarina, Centro Tecnológico. Programa de Pós-graduação em Urbanismo História e Arquitetura.

Florianópolis, 2009.

NOVA TRENTO (Prefeitura). [Site Oficial]. Histórico. 07/07/2014. Disponível em: < https://www.novatrento.sc.gov.br/cms/pagina/ver/codMapaltem/37323>. Acesso em 20/08/2020. 
O ESTADO. Ano XLI, n. 11944. Florianópolis, 21/01/1951. Disponível em: < http://hemeroteca.ciasc.sc.gov.br/oestadofpolis/estadof1915.html>. Acesso em 26/08/2020.

ORTIZ, Renato. Cultura e desenvolvimento. Políticas culturais em revista, v. 1, n. 1, 2008.

PINHEIRO, Marinete; FISCHER, Neide. Salas de sonhos: memórias dos cinemas de Mato Grosso do Sul. Campo Grande: Editora da UFMS, 2008.

POZZO, Renata Rogowski. Uma Geografia do Cinema Brasileiro: bloqueios internacionais, contradições internas. Tese (doutorado) - Universidade Federal de Santa Catarina, Centro de Filosofia e Ciências Humanas. Programa de Pós-Graduação em Geografia. Florianópolis, SC, 2015

. A cotidianidade do cinema. Contracampo, V. 36, n. 3, 2017. Disponível em: < http://dx.doi.org/10.22409/contracampo.v36i3.1002>. Acesso em 16/08/2020.

RAMBO, Gabriela Carolina Dreyer; VIANA, Alice de Oliveira; candeia, Luís Eduardo; BATISTA, Bhrenda Ketlyn. Projeções da modernidade: a arquitetura das salas de cinema de rua de Santa Catarina. XVIII Enanpur - Encontro Nacional da Associação Nacional de Pesquisa em Pós-graduação em Planejamento Urbano e Regional. Natal, 2019. Disponível em:

<http://anpur.org.br/xviiienanpur/anaisadmin/capapdf.php?reqid=1126>. Acesso em 20/08/2020.

RIDENTI, Marcelo. Em busca do povo brasileiro: artistas da revolução, do CPC à era da TV. Rio de Janeiro: Record, 2000.

SANTA CATARINA (Estado). Secretaria de Planejamento. Levantamento aerofotográfico de 1957.

SANTA CATARINA. Departamento Estadual de Geografia e Cartografia. Atlas Geográfico de Santa Catarina. Florianópolis, 1958.

SÃO JOAO BATISTA (Prefeitura). [Site Oficial]. História. 21/03/2017. Disponível em: < https://www.sjbatista.sc.gov.br/cms/pagina/ver/codMapaltem/92318>. Acesso em 20/08/2020.

SILVA, Hadija Chalupe. O Filme nas Telas: a distribuição do cinema nacional. São Paulo: Terceiro nome, 2010.

SIMIS, Anita. Estado e cinema no Brasil. São Paulo: Annablume; Fapesp, 1996.

STEFANI, Eduardo Baider. A geografia do cinema no lazer paulistano contemporâneo: redes e territorialidades dos cinemas de arte e multiplex. Dissertação de Mestrado em Geografia, USP, 2009. 
UNESCO. Cultura e Desenvolvimento. Havana, 2013. Disponível em: <https://unesdoc.unesco.org/ark:/48223/pfooo0221297>. Acesso em 20/08/2020.

VIEIRA, João Luiz e PEREIRA, Margareth Campos da Silva. Espaços do sonho: arquitetura dos cinemas no Rio de Janeiro 1920-1950. Rio de Janeiro, 1982.

VOLTOLINI, Agostinho Cesar. Livro on line família Voltolini. História das famílias Voltolini vindas para Santa Catarina. 2012. Disponível em: < voltolinisc.blogspot.com>. Acesso em 11 de mar. de 2020.

ZANLUCA, Izabela. Rios Urbanos e as bacias hidrográficas: impasses e integração no Vale do Rio Tijucas. Dissertação (mestrado) - Universidade Federal de Santa Catarina, Centro Tecnológico. Programa de pós-graduação em Urbanismo, História e Arquitetura da Cidade. Florianópolis, 2015.

Renata Rogowski Pozzo. Doutora em Geografia. Universidade do Estado de Santa Catarina. Professora Universitária. Rua Coronel Fernandes Martins, 270 -. sul.renate@gmail.com

Luís Eduardo Candeia. Graduando em Arquitetura e Urbanismo. Universidade do Estado de Santa Catarina. Estudante. Rua Coronel Fernandes Martins, 270 Laguna/SC.dudu_lec@hotmail.com

\section{CONTRIBUIÇÃO DE CADA AUTOR}

\section{Renata Rogowski Pozzo}

Conceituação (Conceptualization)

Curadoria de Dados (Data curation)

Obtenção de Financiamento (Funding acquisition)

Investigação/Pesquisa (Investigation)

Metodologia (Methodology)

Supervisão/orientação (Supervision)

Escrita - Primeira Redação (Writing - original draft)

Escrita - Revisão e Edição (Writing - review \& editing).

Luís Eduardo Candeia.

Conceituação (Conceptualization)

Curadoria de Dados (Data curation)

Obtenção de Financiamento (Funding acquisition)

Investigação/Pesquisa (Investigation)

Metodologia (Methodology)

Escrita - Primeira Redação (Writing - original draft)

Escrita - Revisão e Edição (Writing - review \& editing).

Fontes de financiamento: Edital Pibic Udesc/CNPq. 